\title{
Advances in stem cell therapy in Alzheimer's disease: a comprehensive clinical trial review
}

\author{
Nikolaos Karvelas $^{1 \#} \wedge$, Samuel Bennett ${ }^{2 \#}$, Georgios Politis ${ }^{1}$, Nikolaos-Iasonas Kouris $^{1 \wedge}$, Christo Kole $^{1 \wedge}$ \\ ${ }^{1}$ Faculty of Medicine, National and Kapodistrian University of Athens, Athina, Greece; ${ }^{2}$ Emory University School of Medicine, Atlanta, GA, USA \\ Contributions: (I) Conception and design: C Kole; (II) Administrative support: NI Kouris; (III) Provision of study materials or patients: N Karvelas, S \\ Bennett, C Kole; (IV) Collection and assembly of data: N Karvelas, S Bennett, G Politis, NI Kouris; (V) Data analysis and interpretation: N Karvelas, \\ S Bennett, C Kole; (VI) Manuscript writing: All authors; (VII) Final approval of manuscript: All authors. \\ \#These authors contributed equally in this work. \\ Correspondence to: Christo Kole, MD, PhD. Psaron 8, 24100 Kalamata, Greece. Email: christo.kole@gmail.com.
}

\begin{abstract}
Alzheimer's disease $(\mathrm{AD})$ is the most common type of dementia responsible for more than 121,499 deaths from AD in 2019 making AD the sixth-leading cause in the United States. AD is a progressive neurodegenerative disorder characterized by decline of memory, behavioral impairments that affects a person's ability to function independently ultimately leading to death. The current pressing need for a treatment for $(\mathrm{AD})$ and advances in the field of cell therapy, has rendered stem cell therapeutics a promising field of research. Despite advancements in stem cell technology, confirmed by encouraging preclinical utilization of stem cells in $\mathrm{AD}$ animal models, the number of clinical trials evaluating the efficacy of stem cell therapy is limited, with the results of many ongoing clinical trials on cell therapy for AD still pending. Mesenchymal stem cells (MSCs) have been the main focus in these studies, reporting encouraging results concerning safety profile, however their efficacy remains unproven. In the current article we review the latest advances regarding different sources of stem cell therapy and present a comprehensive list of every available clinical trial in national and international registries. Finally, we discuss drawbacks arising from AD pathology and technical limitations that hinder the transition of stem cell technology from bench to bedside. Our findings emphasize the need to increase clinical trials towards uncovering the mode of action and the underlying therapeutic mechanisms of transplanted cells as well as the molecular mechanisms controlling regeneration and neuronal microenvironment.
\end{abstract}

Keywords: Alzheimer's disease (AD); stem cell therapy; embryonic stem cells (ESCs); mesenchymal stem cells (MSCs); induced pluripotent stem cells (iPSCs)

Received: 11 November 2021; Accepted: 27 January 2022; Published: 21 February 2022.

doi: $10.21037 /$ sci-2021-063

View this article at: https://dx.doi.org/10.21037/sci-2021-063

\section{Introduction}

Dementia affects more than 25 million people worldwide, $70 \%$ of whom suffer from Alzheimer's disease (AD); a number which is increasing every year (1). In 2019, more than 121,499 deaths from AD were reported, making $\mathrm{AD}$ the sixth-leading cause in the United States (2) and dementia the seventh-leading cause of death globally (3). $\mathrm{AD}$ is a neurodegenerative disorder characterized clinically by progressive impairment of short-term memory and cognitive disabilities such as personality changes in early stages, which ultimately lead to complete dependence on others in later stages of the disease $(4,5)$. The pathophysiology of $\mathrm{AD}$ is complex and still not completely

^ ORCID: Nikolaos Karvelas, 0000-0003-1452-1192; Samuel Bennett, 0000-0002-4514-4388; Nikolaos-Iasonas Kouris, 0000-0002-1659-

075X; Christo Kole, 0000-0003-4695-3723. 
understood. However, molecular, cellular and genetic evidence supports that at early stages sequential $\beta$ - and $\gamma$-secretase cleavage of the amyloid protein produces $A \beta$ peptides aggregates, especially $A \beta 42$ deposits in the brain, in addition to tau hyperphosphorylation and production of reactive oxygen species. These events lead to synapse loss and neuronal death (6-10). Current knowledge suggests that $A \beta$ generation and accumulation induce changes in synaptic function that may affect fundamental mechanisms of synaptic plasticity (11). Exposure to soluble and fibrillary forms of $A \beta$ is associated with synapse loss $(10,12)$, while exogenous application of oligomeric human $\mathrm{A} \beta$ to organotypic hippocampal cultures induces loss of long-term potentiation (LTP), a form of synaptic plasticity that is believed to be the cellular correlate of learning and memory $(13,14)$. Exogenous application of oligomeric human $\mathrm{A} \beta$ also increases long-term depression (LTD), an activity-dependent reduction in the efficacy of neuronal synapses lasting hours or longer following a long-patterned stimulus (15). These events lead to decreased dendritic spine density and impaired spatial memory (16-18). Further support to this is that synapse loss seems to be higher near the $\mathrm{A} \beta$-aggregates and diminishes with distance (10), suggesting that elevation of $A \beta$ levels in humans could directly perturb synaptic function independently of the aggregation of protein in amyloid plaques. Moreover, $\mathrm{A} \beta$ oligomers may exert some of their adverse effects on synaptic plasticity and memory by binding to receptors (19-21), thereby perturbing or engaging downstream signaling. $\mathrm{A} \beta$ oligomers are also known to engage other signaling pathways, such as the actin-severing protein cofilin and protein phosphatases $\mathrm{PP} 2 \mathrm{~A}$ and $\mathrm{PP} 2 \mathrm{~B} /$ calcineurin, thereby mediating spine loss and synaptic defects $(12,22)$.

Despite advances in the understanding of the pathophysiology of $\mathrm{AD}$, treatment options for the disease are limited. In recent years, breakthroughs in pre-clinical investigations and clinical trials using stem cells have paved the way for new perspectives on studying and treating AD patients (23-25). Stem cells have the unique capacity to self-renew, proliferate, differentiate and to give rise to differentiated cells throughout the lifetime of the organism (26). Due to these properties, these cells are characterized as the most appropriate choice for cell replacement therapies. Several sources of stem cells with different differential capacities have been described so far (27). Totipotent cells, which originate from blastomeres after one or two zygotic divisions, have the ability to give rise to all tissues, ultimately forming the entire organism, including extra embryonic tissues (28). Pluripotent stem cells can give rise to all three germ layers, the endoderm, ectoderm and mesoderm. Embryonic stem cells (ESCs), originating from the inner cell mass (ICM) (29), and induced pluripotent stem cells (iPSCs), which can be generated in vitro through nuclear reprograming of somatic cells (Figure 1), are notable examples of pluripotent stem cells (30). Adult stem cells (ASCs) are undifferentiated cells, characterized as multipotent due to their capacity to give rise only to cells in specific differentiated tissues as a way to replenish dying cells or damaged tissue $(31,32)$. Among the different ASC populations include mesenchymal stem cells (MSC) originating from adipose tissue, umbilical cord and bone marrow (Figure 1) (33-35), and neural stem cells/neural progenitor cells (NSCs/NPCs) (Figure 1) (36). Fetal tissues share similar characteristics with ESCs, although they are not as potent, and, compared to ASCs, exhibit greater proliferation potential and lack of immunogenicity (37). Giving the unique ability of stem cells to develop into any cell type, generation of pluripotent stem cells has offered the possibility of using these cells as a donor source for transplantation therapies. In the present work, we present the latest advances and limiting drawbacks of different sources of stem cell therapy in $\mathrm{AD}$ and offer a comprehensive review of all available registered clinical studies, as documented in clinical trial registries that have been recognized by the International Committee of Medical Journal Editors (ICMJE).

\section{Stem cell types used for AD treatment}

\section{ESCs}

ESCs have an indefinite proliferative life span in vitro while also possessing the ability to give rise to any adult cell in the body (38). Obstacles that limit the use of ESCs in clinical trials include their purification and preservation processes, verification of the pluripotency of the isolated cells, embryonic body formation (38), their tumorigenic capacity and the ethical implications arising from the use of human ESCs (hESCs) stemming from pre-implantation embryos (39). However, their role as source for cellular transplantation in $\mathrm{AD}$ rodent models has been extensively studied.

Pre-clinical studies have successfully generated NPCs from hESCs, using various growth factors and compounds in-vitro (40-44). Regarding their efficacy, several preclinical studies in animal $\mathrm{AD}$ models have shown promising results. Degeneration of neurons and synapses of basal forebrain 


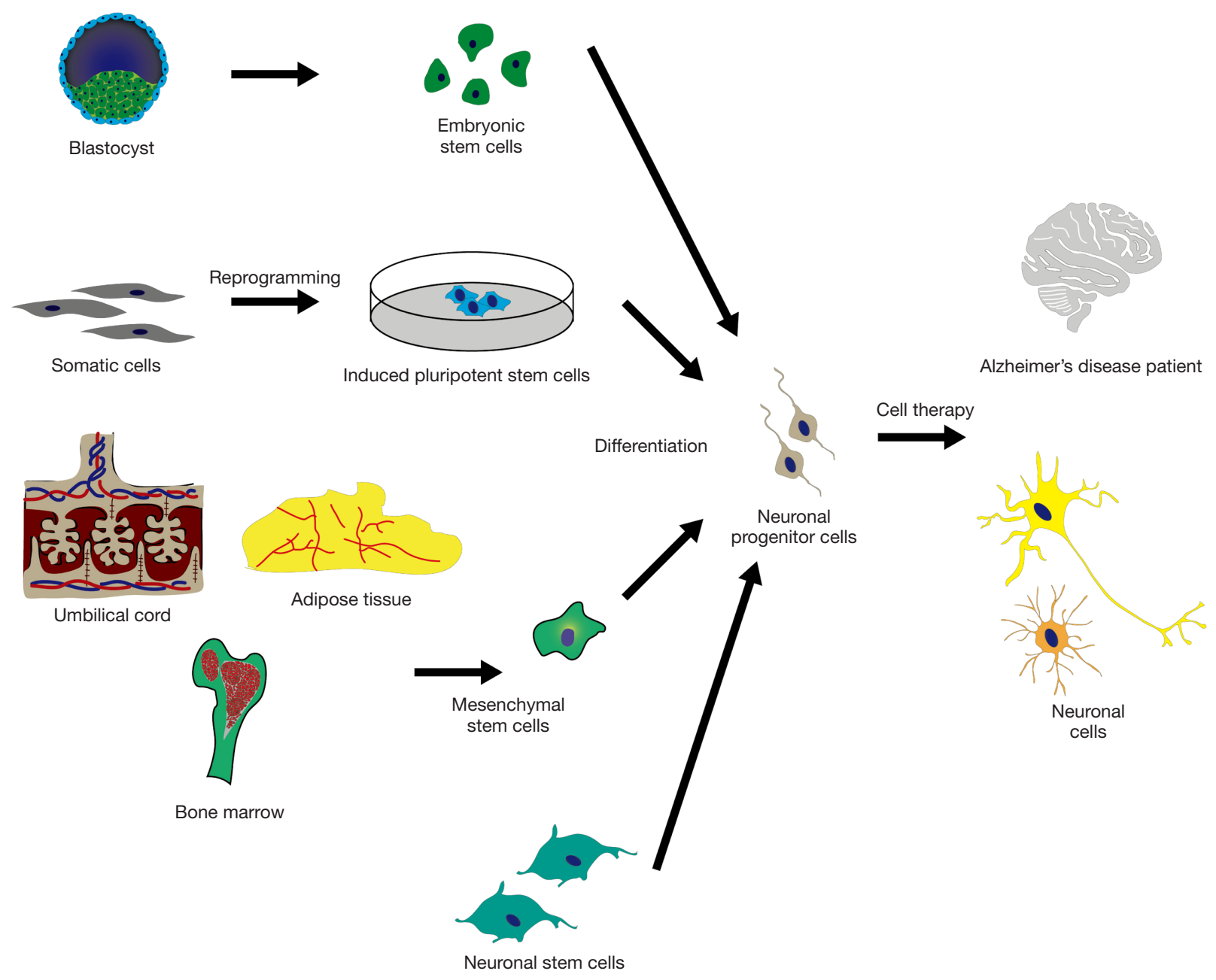

Figure 1 Stem cells therapy originated from various sources currently applied for the treatment of Alzheimer's disease.

cholinergic neurons (BFCNs) throughout the nucleus basalis of Meynert (NBM) causes a pathological cholinergic insufficiency. NBM is a large source of cholinergic innervation to the neocortex and is affected in $\mathrm{AD}(45,46)$, therefore, repopulation of the degenerated BFCNs could be a significant step in improving the cognitive symptoms in $\mathrm{AD}$ patients. BFCNs originating either from mouse or hESCs engrafted successfully to mouse hippocampal slices ex vivo $(44,47)$, and, when transplanted in the brain of 5XFAD and APP/PS1 transgenic mice, improved their learning and memory performances $(44,47)$. The majority of the transplanted cells differentiated into NEUN+ mature neurons and integrated into the cholinergic projection system, and the grafted mice exhibited increased spatial memory when subjected to the Morris Water Maze (MWM) test (47). Moreover, transplantation of hESC-derived medial ganglionic eminence (MGE)-like progenitor cells has been shown to generate adult BFCNs and $\gamma$-aminobutyric acid (GABA) interneurons, resulting in cholinergic innervation in the basal forebrain of $\mathrm{AD}$ mouse model and corrected cognitive impairments (48). Mouse ESCs have also effectively been differentiated into functional cholinergic neuron cell progenitors, which, after transplantation, resulted in increased synapse density and prominent improvement in memory deficits, especially spatial learning assessed via the MWM test, when transplanted into the hippocampus of a Sprague-Dawley rat model with ibotenic acid-lesioned NBM (49).

Embryonic NSCs have also been studied as another possible source of therapeutic cells in $\mathrm{AD}$ mouse models. NSCs are multipotent neural precursors that can differentiate into neurons, astrocytes and oligodendrocytes, 
Table 1 Clinical trials of neural stem cells in patients with AD

\begin{tabular}{|c|c|c|c|c|c|c|}
\hline Intervention & Dosage [n]/route & $\begin{array}{l}\text { Clinical phase/ } \\
\text { identifier }\end{array}$ & $\mathrm{N} \%$ condition & Status & $\begin{array}{l}\text { Main } \\
\text { findings }\end{array}$ & Ref. \\
\hline hNSCs & $\begin{array}{l}\text { (I) Low dose [10]/intranasal; } \\
\text { (II) medium dose [10]/intranasal; } \\
\text { (III) high dose [10]/intranasal; } \\
\text { (IV) placebo [10]/intranasal }\end{array}$ & $\begin{array}{l}\text { NA } \\
\text { ChiCTR2000028744 }\end{array}$ & $\begin{array}{l}\text { 40/AD diagnosis; } 50-75 \text { yo; MMSE } 10-20 \text {; } \\
\text { Improved Hachinski ischemic score } \leq 4 \text {; } \\
\text { Hamilton Psychiatric Rating Scale for } \\
\text { Depression } \leq 10 \text {; Fazekas scale } \leq 2\end{array}$ & $\begin{array}{l}\text { Not yet } \\
\text { recruiting }\end{array}$ & NA & (61) \\
\hline $\begin{array}{l}\text { Autologous } \\
\text { hNSCs }\end{array}$ & NA & $\begin{array}{l}\text { NA/ChiCTR- } \\
\text { ONC-17014171 }\end{array}$ & $\begin{array}{l}\text { 30/AD diagnosis; } 40-80 \text { yo; no blood, } \\
\text { liver, renal or chest pathology }\end{array}$ & $\begin{array}{l}\text { Not approved } \\
\text { by ethics } \\
\text { committee }\end{array}$ & NA & (63) \\
\hline
\end{tabular}

AD, Alzheimer's disease; hNSCs, human Neural Stem Cells; MMSE, Mini-Mental State Evaluation; GDS, Geriatric Depression Scale; MTA, medial temporal lobe atrophy; yo, years old; NA, not applicable.

both in vitro and in vivo $(49,50)$. Different mechanisms explaining the possible disease ameliorating effect of NSCs have been proposed, including neurovascular damage repair (51), immunomodulation via interactions with microglia (52), neuronal replacement, neurotransmitter replenishment, neurotrophic support that promotes synaptic plasticity and cell survival (53). NSCs can either differentiate and generate a mature neuron (direct neurogenesis) or first differentiate into neural NPCs (indirect neurogenesis) (54). Reinforcement of synaptic repair and protection of cholinergic neurons in the basal forebrain were induced after transplantation of embryonic mouse NSCs into APP/ PS1 mice hippocampi (55). In a similar study, embryonic mouse NSC implantation significantly reduced microgliosis, astrogliosis, and decreased glial markers, toll-like receptor 4 (TLR4) and proinflammatory cytokine (IL-1, IL-6, TNF- $\alpha$ and PGE2) expression (56). Despite the encouraging results in preclinical studies, the use of hESCs as the primary source of stem cells in clinical trials has not been documented.

\section{Fetal and adult NSCs}

Fetal-originating human CNS-derived NSCs (huCNS-SC) have been the main source of stem cells in only a few studies. They have demonstrated successful engraftment, migration and differentiation properties when transplanted in the lateral ventricles of NSE/APPsw transgenic $\mathrm{AD}$ model mice (57). Reduction of tau phosphorylation and $A \beta$ production via BASE1 expression, deactivation of microglia and consequent decrease of neuroinflammation, and attenuation of apoptotic signals, which induced synaptic plasticity were observed. Furthermore, transplanted mice exhibited spatial memory improvement compared to the control group (57). The effects of fetal huCNS-SCs in $\mathrm{AD}$ pathology have also been reported by a different group, which showed an increase of synaptic connectivity markers synaptophysin, synapsin, and growth-associated protein-43 (GAP-43) in AD mice hippocampi, but with no changes in $A \beta$ and tau pathology (58). The transplantation of an engineered human cortex-derived NSC line (NSIHK532-IGF-1) in the fimbria fornix of an APP/PS1 mouse model provided proof-of-concept for efficient production of neurotrophic factors and activation of microglia. Significant improvement was noticed in regard to spatial learning, short-term non-associative and longterm memory (59). However, in a study examining longterm behavior of huCNS-SC in the Rag- 5 xfAD mice hippocampus, the NSCs, despite successful engraftment, had failed to differentiate into mature cells 5 months posttransplantation. Furthermore, non-neoplastic ectopic clusters were discovered in the lateral ventricle, and no improvement in cognitive performance was observed (60).

Clinical trials testing these types of stem cells have been documented only in the Chinese Clinical Trial Registry (Table 1). A single center randomized, double-blind trial will evaluate safety and efficacy of the ANGE004 human neural stem cells (hNSCs) (ChiCTR2000028744). Three groups, each consisting of 10 patients, will receive a low, medium or high dose of hNSCs intranasally, whereas 
another group will receive a placebo drug. Primary and secondary outcomes will consist of adverse events and neuropsychological measures (61). A different randomized, double-blind study (ChiCTR2000039011) with a similar design will recruit 36 patients and assess the safety and efficacy of intranasal hNSC administration (62). Notably, an open label study (ChiCTR-ONC-17014171) aimed to examine the feasibility of autologous NSCs administration, but it has not obtained approval from the ethics committee yet (63).

\section{Mesenchymal and hematopoietic stem cells}

Among the different ASC lines, mesenchymal and hematopoietic stem cells can be easily obtained and thus have been the ones most widely studied as possible therapeutics for AD. MSCs are hierarchical postnatal stem cells, capable of self-renewing and retaining diverse differentiation potency (64). MSCs may be isolated from multiple sources and can differentiate into multiple types of tissue, have high expansion capacity and low immunogenicity and carcinogenic potential $(65,66)$. Concerning their effects in $\mathrm{AD}$ pathology, MSCs have been reported to enhance neurogenesis through the release of neurotrophic factors, enhance $A \beta$ clearance, modify innate and adaptive immune cell responses through upregulating neuroprotective cytokines such as IL-10 while decreasing the amount of pro-inflammatory cytokines TNF- $\alpha$ and IL-1 $\beta$ (56,67-70). Reduction in amyloid-beta deposition and increased microglial phagocytic activity has also been observed (71,72).

Human umbilical cord originated MSCs (UC-MSCs) can be collected from the cord lining and Wharton's jelly, with the latter being more accessible and commonly used (73). Multiple preclinical studies have assessed their efficacy and mechanism of action. APP/PS1 mice injected with human UC-MSCs directly in the carotid artery exhibited successful migration of stem cells to the brain parenchyma, reduced amyloid burden, activated microglia in the hippocampus and cortex, and improved cognitive performance at sensorimotor tasks compared to controls (74). Similar results were reported also by Xie et al., suggesting that hUC-MSCs improved spatial learning and memory in APP/PS1 mice (75). Intravenous administration of hUC-MSC in Tg2576 mice reduced oxidative stress and promoted neurogenesis in the hippocampus leading to better performance in the MWM test. However, levels of $A \beta$ and $A \beta$-cleaving enzymes were not significantly affected compared to control mice (76). Lipopolysaccharide (LPS) has been shown to decrease the density of $\alpha 7 \mathrm{nAChRs}$ and nucleated cell numbers in the hippocampus and striatum, while stimulating the accumulation of $\mathrm{A} \beta$ [1-42] peptides, astrocytosis, and episodic memory decline, creating an $\mathrm{AD}$ like phenotype in mice (77). hUC-MSCs prevented the pathogenic effects of bacterial LPS damage and retained episodic memory in C57BL/6 J mice due to reduction of neuro-inflammation (78).

Multiple clinical studies examining possible therapeutic benefits of hUC-MSCs in AD patients have been documented (Table 2). The NEUROSTEM ${ }^{\circledR}$-AD treatment (Human Umbilical Cord Blood Derived Mesenchymal Stem Cells) in an open label phase I trial (NCT01297218) resulted in no serious adverse events and no dose-limiting toxicity neither during the first 12 -week $(79,80)$ nor at the long-term, 24-month follow-up period, which was evaluated in a phase I/IIa (NCT01696591) clinical trial (81). Moreover, the authors reported that stereotactic administration of hUCB-MSCs into the hippocampus and precuneus was feasible, safe, and well tolerated (79). The data suggested faster cognitive decline of the subjects than typical $\mathrm{AD}$ progression however, which the authors attributed to the early-onset stage of the disease. Due to small sample size and lack of control group, no safe conclusion could be reached on efficacy (81). Another double-blind, single-center, phase I/IIa clinical trial (NCT02054208) investigated the safety, dose limiting toxicity, and exploratory efficacy of three repeated intra-cerebro-ventricular (ICV) administrations of NEUROSTEM $^{\circledR}$ (82). This study consisted of two stages: during the first one, which was open label, participants were divided between a low- and high-dose group. In the second, double-blind and randomized stage, patients were assigned to either a high-dose or placebo group. Adverse effects and neuropsychological score modifications (ADASCog, MMSE and others) 24 weeks post-treatment were the measured outcomes (82). To date, results have been provided for the first stage of this study. There were 3 patients assigned to the low-dose and 6 to the high-dose group. hUCB-MSCs were infused through an Ommaya reservoir directly to the right lateral ventricle three times, once every 4 weeks. No implantation side effects were documented, however, all participants developed fever following hUCB-MSCs administration, which did not persist for more than 36 hours and resulted in no complications. Transient leukocytosis was also noted in the cerebrospinal fluid (CSF), with higher WBC count for 


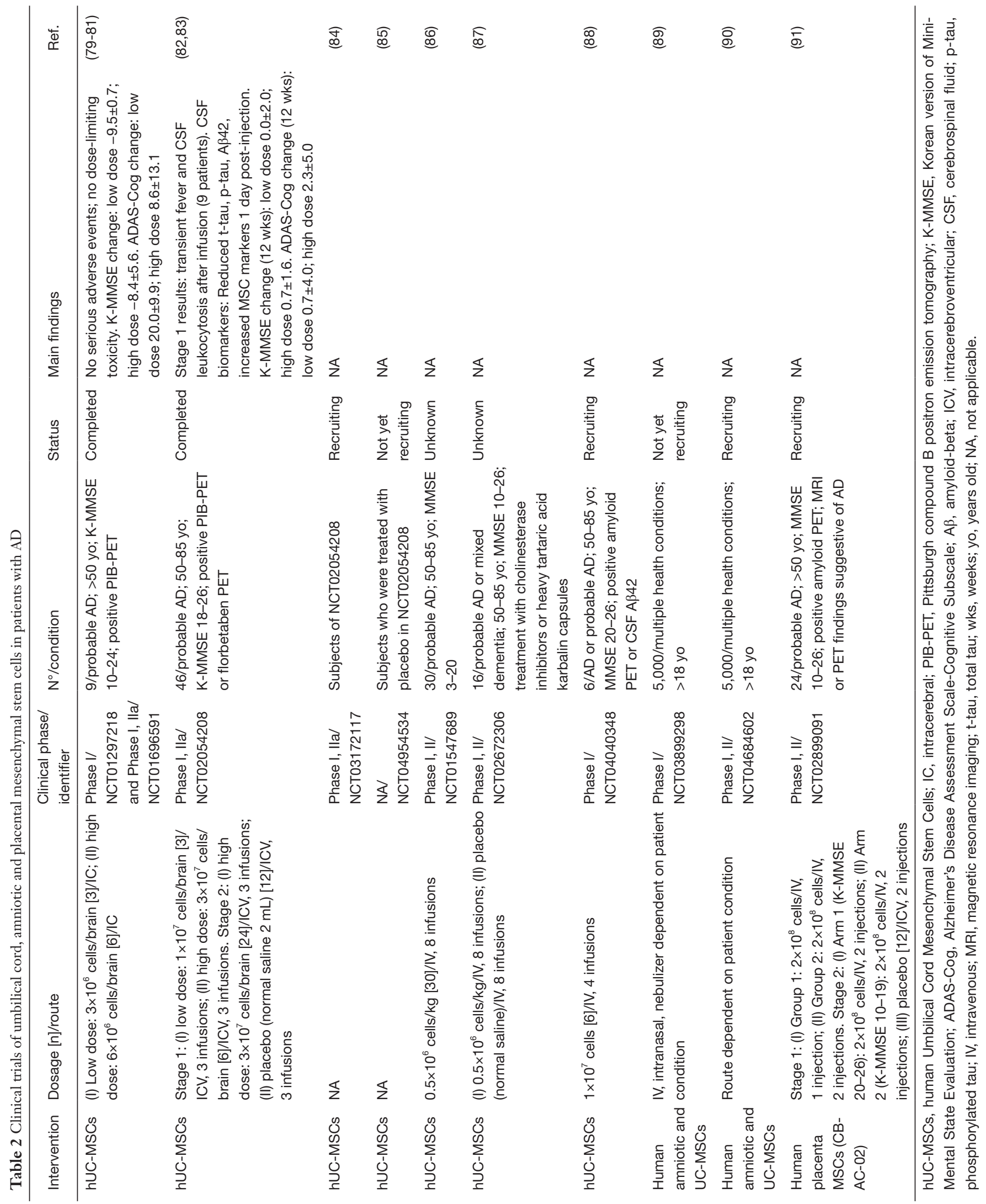


the high-dose group. These immunological reactions were attributed to the MSCs, despite evidence that they possess low immunogenic potential. As for efficacy, reduced CSF biomarkers (total tau, p-tau, A $\beta 42$ ) and increased MSC biomarkers (Galactin-3, sICAM-1, progranulin, GDF-15) were observed 1 day after injection, but were not observed again at the 4-week checkpoint, which the authors attributed to the short lifespan of MSCs (83). Moreover, a follow-up study will assess neuropsychological scores, imaging findings and CSF biomarkers in these participants in a phase-I/IIa Clinical Trial (NCT03172117) (84), and a second follow-up study will quantify neuropsychological parameters and CSF biomarkers in the NCT04954534 study control group (85).

Two other studies, an open-label, single-center phase I/ II clinical trial (NCT01547689) (86) and a randomized, double-blind, placebo-controlled and multi-center phase I/II trial in China (NCT02672306) (87) aim to investigate the effects of intravenously administrated hUC-MSCs in 30 and 16 patients respectively, assessing adverse events and various neuropsychological and biochemical parameters. Another prospective open label phase I study (NCT04040348), currently on recruiting status, will comprise of multiple intravenous infusions of allogeneic hUC-MSCs on 6 patients with probable $\mathrm{AD}$ and positive $\mathrm{A} \beta$ markers. The number of serious adverse events will be the primary outcome, and neuropsychological, CSF and serum biomarkers (Apolipoprotein E, A $\beta 40, \mathrm{~A} \beta 42$, plasma renin activity, etc.) and MRI volumetry the secondary outcomes (88). Additionally, a phase I trial by R3 Stem Cell (NCT03899298) (89) and a second one by Thomas Advanced Medical using the PrimePro ${ }^{\mathrm{TM}} / \mathrm{PrimeMSK}^{\mathrm{TM}}$ therapeutic regimen (NCT04684602) (90) will evaluate human amniotic and umbilical cord MSCs in various health conditions, including neurological ones. No details on the specific protocol for $\mathrm{AD}$ patients have been published. For the AD cohort, MMSE scores and quality of life will be measured at various time points post-procedure, from 1 month up to 10 years.

The placenta has been reported to be another potent source of MSCs (64). The safety and potential therapeutic effects of CB-AC-02 (human placental MSCs) intravenous transplantation will be evaluated in a phase I/IIa clinical trial (NCT02899091), which is currently recruiting participants (91). This randomized trial will enroll 24 patients with probable $\mathrm{AD}$, positive amyloid on amyloid-ligand positron emission tomography (PET) and imaging findings on MRI or PET scan. The trial will be divided in two stages: the first will evaluate two different administration schemes (one or two injections of the same dose) whereas the other will assess the effect of the same dosing scheme in two different arms of patients with K-MMSE 20-26 and 10-19 respectively. Both of these stages will be compared to a third, placebo-administered arm. Outcomes will be measured over 48 weeks, with the primary deliverable being the number of adverse events, while secondary outcomes will include changes in ADASCog, K-MMSE and other neuropsychological batteries, A $\beta$ and tau in CSF, MRI, PET and qEEG (91).

Adipose-derived SCs (ADSCs) have been extensively studied, since adipose tissue poses an accessible reservoir of MSCs (92). ADSCs administered intracerebrally in APP/ PS1 mice resulted in reduced $A \beta$ deposition, microglia activation and enhanced cognitive function, assessed via MWM and novel object recognition (NOR) tests (93). Intravenous infusion of human ADSCs in Tg2576 AD model mice presented similar effects, as well as secretion of antiinflammatory and neurotrophic factors (94). A study aiming to improve the efficacy of ADSC implantation pre-treated them with melatonin. After injecting a dose in Wistar rats intravenously, the study reported better performance in MWM and NOR tests for the melatonin pre-treated ADSC rats compared to the ADSC administered rats (95).

Preclinical evidence has been translated to several ongoing clinical trials (Table 3). A phase I trial of autologous adipose-derived stromal vascular fraction (ADSVF), a source of both ADSCs and hematopoietic stem cells, studied the safety of ICV injections in 31 neurological patients, among them 10 with $\mathrm{AD}$ who had failed all previously available therapeutic options (96). Patients were selected according to the criteria of a previous ADSVF safety trial, in which ADVSF was administered intravenously or intraarticularly (NCT01953523) and which has no published results (97). Cells were administered every $2-3$ months through an implanted Ommaya reservoir or through an existing functioning VP shunt. The only concerning side effects that were reported were mild headache and pain at surgical incisions lasting less than 24 hours. Of the $\mathrm{AD}$ patients, 8 remained stable or improved in cognitive tests, 3 showed reduced phospho-tau and $\mathrm{A} \beta$ burden in CSF, and, in one case, the hippocampal volume increased from less than 5 th percentile to 48 th percentile after 8 stromal vascular fraction (SVF) injections (96).

In a randomized, double-blind, placebo-controlled and parallel-group comparison phase I/IIa trial (NCT03117738), the safety and efficacy of AstroStem 
Table 3 Clinical trials of adipose-derived mesenchymal stem cells in patients with $\mathrm{AD}$

\begin{tabular}{|c|c|c|c|c|c|c|}
\hline Intervention & Dosage [n]/route & Clinical phase & $\mathrm{N} \%$ conditions & Status & Main findings & Ref. \\
\hline ADSVF & $\begin{array}{l}\text { Route dependent on } \\
\text { patient condition }\end{array}$ & NA/NCT01953523 & $\begin{array}{l}3,000 / \text { multiple health } \\
\text { conditions; >16 yo }\end{array}$ & Completed & NA & $(97)$ \\
\hline $\begin{array}{l}\text { Autologous } \\
\text { ADSCs } \\
\text { (AstroStem) }\end{array}$ & $\begin{array}{l}\text { (I) Autologous ADSCs } \\
\text { [11]/IV, } 9 \text { injections; } \\
\text { (II) placebo (saline with } \\
30 \% \text { auto-serum) [10]/ } \\
\text { IV, } 9 \text { injections }\end{array}$ & $\begin{array}{l}\text { Phase I, II/ } \\
\text { NCT03117738 }\end{array}$ & $\begin{array}{l}\text { 21/probable AD; >50 yo; } \\
\text { MMSE 16-26 }\end{array}$ & Completed & $\begin{array}{l}\text { No adverse events } \\
\text { reported; ADAS-Cog } \\
\text { change: Astrostem } \\
+5.9 \pm 6.8 \text { placebo } \\
+3.0 \pm 5.4 \text {; MMSE change: } \\
\text { Astrostem }-3.4 \pm 2.8 \\
\text { placebo }-1.4 \pm 2.8\end{array}$ & (98) \\
\hline $\begin{array}{l}\text { ADSCs (HB- } \\
\text { adMSCs) }\end{array}$ & $\begin{array}{l}2.0 \times 10^{8} \text { cells } / \mathrm{IV} \\
4 \text { injections }\end{array}$ & $\begin{array}{l}\text { Phase I, Ila/ } \\
\text { NCT04228666 }\end{array}$ & NA & $\begin{array}{l}\text { Withdrawn } \\
\text { due to } \\
\text { COVID }\end{array}$ & NA & (100) \\
\hline ADSCs & NA & NA/NCT04855955 & $\begin{array}{l}\text { Later stage AD with } \\
\text { severe cognitive } \\
\text { disability; failure of } \\
\text { current medical therapy }\end{array}$ & Available & NA & $(103)$ \\
\hline MSCs-Exos & $\begin{array}{l}\text { (I) Low dose: } 5 \mu \mathrm{g} / \text { nasal } \\
\text { drip, } 2 \text { per week for } \\
12 \text { wks; (II) medium } \\
\text { dose: } 10 \mu \mathrm{g} / \text { nasal drip, } \\
2 \text { per wk for } 12 \mathrm{wks} \text {; (III) } \\
\text { high dose: } 20 \mu \mathrm{g} / \mathrm{nasal} \\
\text { drip, } 2 \text { per week for } \\
12 \text { wks }\end{array}$ & $\begin{array}{l}\text { Phase I, II/ } \\
\text { NCT04388982 and } \\
\text { ChiCTR2000032579 }\end{array}$ & $\begin{array}{l}\text { 9/mild or moderate AD; } \\
\text { >50 yo; MMSE } 10-24 ; \\
\text { modified Hachinski } \\
\text { Ischemic scale }<4 ; \\
\text { suspension of cognitive- } \\
\text { enhancing drugs }\end{array}$ & Recruiting & NA & $(104,105)$ \\
\hline
\end{tabular}

AD, Alzheimer's disease; ADSVF, adipose-derived stromal vascular fraction; SVF, stromal vascular fraction; ICV, intracerebroventricular; CSF, cerebrospinal fluid; yo, years old; NA, not applicable; ADSCs, adipose-derived Stem Cells; IV, intravenous; ADAS-Cog , Alzheimer's Disease Assessment Scale-Cognitive Subscale; MMSE, Mini-Mental State Evaluation; wks, weeks; HB-adMSCs, Hope Biosciences autologous Mesenchymal Stem Cells; MSCs-Exos, Exosomes Derived from Allogenic Adipose Mesenchymal Stem Cells. 
(autologous ADSCs) was evaluated (98). 11 participants were treated with AdMSC while the placebo-control group, consisting of 10 participants, received saline with $30 \%$ auto-serum. At 30 week-follow up, patients receiving ADSCs reported higher ADAS-Cog score change (5.9 \pm 6.8$)$

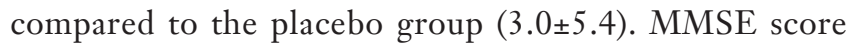
change was reported at $-3.4 \pm 2.8$ and $-1.4 \pm 2.8$ for the ADSC and placebo group, respectively. A randomized, doubleblind, active-controlled phase IIb trial (NCT04482413) is currently evaluating the effect of AstroStem and donepezil treatment on 80 participants, similarly to the previous study (99). Treatment group will be administered via intravenously AstroStem which consists of two syringes and each syringe contains $2.0 \times 10^{\wedge} 8$ cells $/ 20 \mathrm{~mL}$ of saline with $30 \%$ auto-serum while the active control group will receive $5 \mathrm{mg}$ of Donepezil and AstroStem Placebo. ADAS-Cog score will be measured as the primary outcome, and other neuropsychiatric scores as secondary ones.

An open-label, non-randomized phase I/IIa (NCT04228666) evaluating the safety profile of four IV infusions of ADSCs in patients with a clinical diagnosis of $\mathrm{AD}$ was withdrawn due to the COVID-19 pandemic (100). The primary endpoint of this study was to measure the number and frequency of adverse events throughout the study duration by obtaining a basic metabolic panel and complete blood count, while the second endpoint of this study was to evaluate the ability of ADSCs to alter ADrelated inflammation by obtaining levels of TNF-a, IL-1, IL-6, C-reactive protein (CRP) and A $\beta 40, A \beta 42$ serum levels (100). Furthermore, a large open-label, nonrandomized trial (NCT03297177) will evaluate the safety and efficacy of autologous microvasculature stem/stromal cell isolates acquired from subdermal fat deposits in 300 patients with various neurologic diseases, among them $\mathrm{AD}$ (101). Cells will be collected via microcannula, adiposederived tissue stromal vascular fraction will be isolated using the Centricyte 1000 closed system and, following re-suspension in saline, will be delivered intravenously in patients. Adverse and severe adverse events 6 months to 5 years post-intervention will serve as the primary outcome, while neurological function testing and MRI scans will constitute secondary outcomes (101). Another clinical trial in Japan (jRCTb030190214) that would examine the effects of autologous ADSC intravenous administration in 36 patients has been suspended (102). Finally, a recently indexed expanded access study (NCT04855955) of ADSCs will be aimed towards people with severe AD. No details on dosing and checkpoint outcomes has been published as of the time this manuscript is submitted (103).

Administration of ADSC extracellular vesicles, also known as exosomes, has appeared as a promising alternative to whole-cell transplantation (106). Exosomes are naturally occurring nanosized vesicles and comprised of natural lipid bilayers with the abundance of adhesive proteins that readily interact with cellular membranes (107). ADSC-exosomes administrated in APP/PS1 mice promoted neurogenesis, decreased $A \beta$ plaques and rescued memory deficit in the model mice (106). Two studies, an open-label phase I/II (NCT04388982) and ChiCTR2000032579 clinical trials, currently on recruitment status will evaluate the safety and efficacy of exosomes derived from allogenic adipose MSCs (MSCs-Exos) in patients aged over 50 with mild or moderate $\mathrm{AD}(104,105)$ (Table 3). Both studies will evaluate the liver/kidney function laboratory values and adverse events as primary outcome measures, and ADAS-Cog score, quality-of-life evaluation, MRI and PET-CT neuroimaging the secondary ones $(104,105)$.

Bone marrow MSCs (BM-MSCs) are usually incorporated, alongside ADSCs, as stem cell treatments in various disease models, due to their accessibility (108). Human BM-MSCs transplanted in the lateral ventricles of $3 \times \mathrm{Tg}-\mathrm{AD}$ model mice preserved their working memory, examined via the MWM test, in contrast to saline-treated mice (109). Concurrently, reduced levels of A $\beta 56$ and preserved levels of glutamine synthase were detected in the entorhinal cortex, while neurogenesis was induced in the subventricular zone (SVZ) (109). Oxygen deprivation of human BM-MSCs resulted in the production of negligible levels of HLA-DR antigen and higher migratory capacity (110). IV or intranasal administration of these ischemia-tolerant cells in APP/PS1 mice resulted in reduction of soluble cerebral $A \beta$ levels and plaques, an increase in $\mathrm{A} \beta$-cleaving enzyme levels and an amelioration of neuroinflammation (110). In APdE9 AD model mice, BM-MSCs improved spatial memory and repaired neuronal amyloid-induced damage by activating microglia against plaques and suppressing oxidative stress (111). Intravenous administration of BM-MSCs in APP/PS1 mice enabled them to migrate in the brain parenchyma and target sites of inflammation, promoting $\mathrm{pE} 3-\mathrm{A} \beta$ plaque size reduction, microglia activation and inflammation and growth factor decrease (72). BM-MSCs have also been reported to secrete the anti-inflammatory microRNA miR-146a, which, when taken up by astrocytes in the hippocampi of APP/PS1 mice, resulted in decreased gliosis and pro-inflammatory cytokine expression. In another study, multiple BM-MSC 
intravenous injections in $3 \times \mathrm{Tg}-\mathrm{AD}$ mice, in addition to attenuating neuroinflammation and inhibiting $\beta$-secretase activity, significantly reduced total and phosphorylated tau burden (112). Finally, in a study on $5 x F A D$ mice that aimed to determine the optimal location for BM-MSC brain implantation, comparison of transplantation into the lateral ventricles, the hippocampus, and into both of these regions showed the greatest effectiveness in the case of lateral ventricle injection (113). Similar phenomena have been observed in other preclinical studies utilizing BMMSCs $(114,115)$. Apart from bone marrow allocated MSCs, human menstrual blood-derived MSCs (MenSCs) have been recently reported to have multiple beneficial effects in APP/PS1 mice and may improve symptoms of AD by reducing amyloid plaques and phospho-tau, and increasing A $\beta$-degrading enzyme activity and immunomodulatory effects, resulting in overall better cognitive status (116).

These encouraging preclinical results have led to the development of numerous clinical trials (Table 4). A prospective, randomized, double-blinded phase I study (NCT02600130) is currently evaluating the safety and efficacy of Longeveron Allogeneic Human Mesenchymal Stem Cell (LMSCs) for the treatment of patients with clinically diagnosed AD (117). Thirty-three participants aged 50-80 were randomized in a 2:2:1 ratio to receive intravenously either low-dose (20 million) or high-dose (100 million) Longeveron MSCs or placebo, respectively. Incidence of treatment-related adverse events will be recorded as primary outcomes, while preliminary efficacy measures, including ADAS-Cog scores, quality-of-life assessments, blood and CSF biomarkers and MRI volumetry have been defined as the secondary outcomes (117). The effect of allogeneic BM-MSCs are also being evaluated in a multi-center, randomized, single-blind; crossover phase IIa trial (NCT02833792) (118), using ischemia-resistant MSCs. Patients aged 55-80 years with a mild to moderate dementia diagnosis in accordance with the NINCDSADRDA criteria, and MMSE score between 12 and 24 will be assessed for possible adverse events and neurocognitive test scores after treatment (118). Another multi-center, nonrandomized, open-label study (NCT03724136) currently on recruiting status, will assess the use of autologous BMMSCs in AD and autism-spectrum disorders (119). One hundred patients with a documented diagnosis of dementia or autism-spectrum disorder and, in the case of dementia, a MMSE score of 24 or less, are eligible to take part. Participants will then be assigned to one of three arms. The first arm will be administered 14 cc of BM-MSC fraction intravenously, the second will also undergo near infrared light treatment using an FDA approved device on the preand the first post-operative day at the frontal area, and the third will be administered, combined with BM-MSCs intravenously, a $1 \mathrm{cc}$ of BM-MSC fraction intranasally. MMSE scores will be the primary outcome for $\mathrm{AD}$ and dementia patients, with a goal of a 3 -point improvement over the 1-year follow up, and secondary outcomes will consist of qualitative data about daily activities and quality of life, as described by the patients, friends and family (119). Finally, an open-label phase IIa study will attempt to evaluate the safety and efficacy of the $\mathrm{NurOwn}^{\circledR}$ autologous MSCs Secreting Neurotrophic Factors (MSC-NTF cells) (EUCTR2020-002872-11-NL) (120). 40 prodromal or mild AD patients will be recruited and administered 3 doses of the therapeutic regimen intrathecally. Adverse events, functional and metabolic alterations will comprise the primary outcomes, whereas CSF and blood biomarkers of neurodegeneration and inflammation will comprise the secondary outcomes. Notably, the Elecsys system will be used to quantify $\mathrm{AD}$ biomarkers (120).

Peripheral blood is a known means of obtaining HSCs, as well as MSCs. Granulocyte colony stimulating factor (G-CSF), also known as filgrastim, has been used to mobilize both MSCs and HSCs from the bone marrow into peripheral blood. It has been widely used for treatment of patients who have a deficiency of white blood cells, and thus has a known safety profile (123). Also, it has been routinely used to stimulate and mobilize stem/progenitor cells for bone marrow transplantation in animal studies $(124,125)$. G-CSF was first shown to promote neurogenesis, hippocampal $\mathrm{A} \beta$ load reduction and cognitive repair in Tg APP/PS1 mice (126). In Tg2576 mice, G-CSF administration caused BM-MSC/HSC brain infiltration through CXCR4/SDF-1 chemotactic signals, with BMMSCs specifically contributing to the replenishment of astrocytes and oligodendrocytes where improvement of cognitive function was noted (127).

A randomized phase I/II clinical trial (NCT01617577) evaluated G-CSF as a treatment option for $\mathrm{AD}$ in 8 patients over 55 years, with a probable $\mathrm{AD}$ and MMSE score between 10 and 24 (121). Patients received G-CSF subcutaneously at a dose of $10 \mathrm{mg} / \mathrm{kg}$ daily for 5 days, and placebo (D5W or $5 \%$ dextrose solution) for 5 days at crossover time, while the second group ( 3 participants) followed the opposite plan (placebo followed by G-CSF). Primary outcomes consisted of ADAS-Cog and Paired Associate Learning memory score (PALmem), and PAL scores adjusted for total trial 


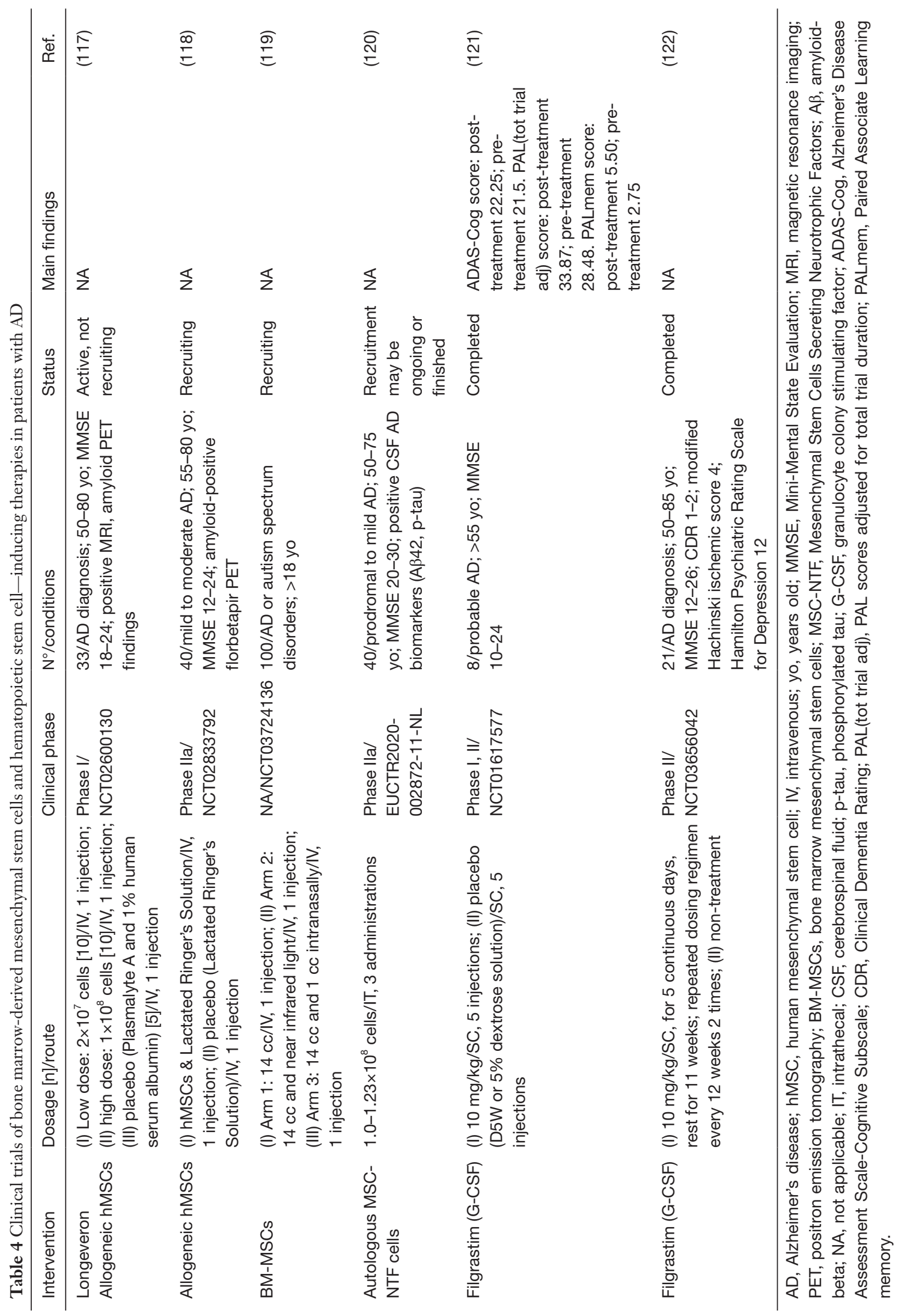


duration [PAL(tot trial adj)], which would be measured before treatment (baseline), at 2 weeks and 4 weeks post each intervention, as well at the end of the trial at 14 weeks. Decreased ADAS-Cog and PAL(tot trial adj) and increased PALmem scores indicate an improvement in cognitive function. Treatment with G-CSF resulted in a mild decrease in ADAS-Cog (22.25 to 21.5) and PAL(tot trial adj) score (from 33.87 to 28.48), however these changes were not statistically different between G-CSF and placebo group. PALmem scores on the other hand, showed an increase from initial 2.75 to 5.50 at 4 weeks post treatment $(\mathrm{P}=0.034)(121)$. A second study (NCT03656042) investigating G-CSF versus no treatment in $21 \mathrm{AD}$ patients investigated ADAS$\mathrm{Cog}$ as the primary outcome and various neuropsychological inventories, CD34+ cell numbers, which correspond to HSCs, and MRI volumetry as secondary outcomes. No results have been published yet (122).

\section{iPSCs}

The ability to reprogram somatic cells through reversal to a pluripotent state has enabled us to produce iPSCs (128). The study by Yamanaka $e t$ al. implemented transcription factors $O c t 3 / 4$, Sox 2, Klf4, and $c-M y c$, to generate iPSCs from murine embryonic and adult fibroblasts in 2006 (129), and then by human fibroblasts in 2007 (130). The produced iPSCs exhibit many similarities with ESCs, at the phenotypical, genetic, epigenetic, and transcriptomic level $(129,130)$, but they also display subtle functional differences. For instance, they have a lower tendency to differentiate along hematopoietic, neuroepithelial and neuronal lineages (128). Regarding neurological applications, iPSCs posit a probable source of NSCs and NPCs, with both neurogenic and gliogenic potential $(131,132)$. Use of iPSCs in AD animal models has shown promising results (133). Conversion of human iPSCs into cholinergic NPCs and transplantation in PDAPP transgenic mouse hippocampi yielded significant results regarding spatial memory improvement when the animals underwent the MWM test (134). A follow-up study from the same group attributed this effect to increased populations of human and mouse ChAT-, vesicular GABA transporter (VGAT)and alpha7 nicotinic acetylcholine receptor ( $\alpha 7 \mathrm{nAChR})$ positive neurons in the hippocampus and throughout the cortex (135). Another group investigating the same approach recently published their results on iPSC-derived $\mathrm{NPC}$ transplantation in the hippocampi of $3 \mathrm{x} T \mathrm{Tg}-\mathrm{AD}$ mice. Treated mice exhibited an improvement in learning and memory capacity in an Object Location Task (OLT) and in Barnes maze, as well as a reduction in AD pathology and synaptogenesis (136). Another investigation in 5XFAD AD mouse models tested the direct transplantation of mouse protein-iPSCs, which, after engraftment, differentiated into microglia, astrocytes, and oligodendrocytes. This resulted in reduction of $A \beta$ plaques and better performance on the Y-maze test compared to saline-injected controls but had no effect on neuronal loss (137). An immunologic strategy was implemented in another study, in which macrophage-like cells expressing Neprilysin-2, a protease against $\mathrm{A} \beta$, were engineered from human iPSCs, and administered intracerebrally in 5XFAD mice. A decrease in A $\beta 1-42$ concentrations in the interstitial fluid was noted, in comparison to controls and cells that did not express Neprilysin-2 (138). Despite the promising results, iPSCs have not entered clinical trials against $\mathrm{AD}$ yet, due to complications such as tumor formation, immune rejection and glial scar formation in the CNS (133). Nevertheless, in one study, clinical-grade induced huNSCs were successfully generated from human iPSCs and were transplanted in immunodeficient mice, and exhibited no tumorigenic activity (139).

\section{Limitations and obstacles}

Research on stem cell-based therapies is accelerating, and every year more and more potential treatments find their way to clinical trials. Despite the gain in momentum, several translational limitations need to be overcome before this type of treatment becomes widely available. Important factors that must be considered beforehand include the nature of the CNS and AD per se and the methodology of stem cell treatment.

Some inherent properties of neuronal networks pose significant challenges to cell-based approaches. Histologically, brain tissue is characterized by extensive diversity of cell phenotypes (140) with synaptogenesis established early during development giving rise to complex networks (141). The fate and properties of endogenous NSCs localized at the subgranular zone (SGZ) of the hippocampal dentate gyrus and SVZ of the lateral ventricle wall are finely regulated by factors of their microenvironment, called the neurogenic niche, which maintains a dynamic balance by keeping the NSCs in a static, undifferentiated dormant state (142-144). NSCs can be activated to proliferate, migrate, and differentiate when exposed to stimuli such as brain damage; however, 
this endogenous cell activation is insufficient and incapable of replacing damaged functional nerve tissue sufficiently (145-147). On the other hand the efficiency of exogenous stem cell transplantation therapy is still controversial, mainly due to the low grafting efficiency of exogenous stem cells in the brain (less than 5\%) (146). An increase in stem cell survival may be achieved by incubation of grafted cells with neurotrophic factors, as shown by Rockenstein, Lilja et al. $(148,149)$. NSCs treated with neurotrophiclike factor [Cerebrolysin (CBL)] prior to transplantation in transgenic model mice increased the survival of NSCs, as well as furin levels, which promotes the processing of pro-brain derived neurotrophic factor (pro-BDNF) into BDNF in the grafted cells (149). Moreover, administration of human NSC cells to a neurotrophic factor pretreated mouse enhanced the population of early neurons expressing doublecortin (DCX+) and decreased $\mathrm{A} \beta$ levels significantly (148). Migration of transplanted cells from the injection site and the affected sites is crucial for a therapeutic effect in the CNS (150), however transplanted hNSCs tend to create cell clusters in the injection site resulting in limited migration ability (151). This is mainly due to lack of organized and diffuse radial glia guiding NSCs to the appropriate location $(152,153)$ as well as the expression of chemotactic signals which lead to NSCs clustering (154).

$\mathrm{AD}$ further contributes to the complexity of the issue at hand. In this disease, microglial activation results in neuronal damage and progressive tau accumulation, which promotes neurodegeneration (155). The above changes have been shown to significantly affect neurogenic niches and stem cell fates. In multiple studies, $A \beta$ aggregates have led to glial differentiation of NSCs in cell lines and transgenic mouse models $(156,157)$. Additionally, neuronal injury stimulates the hypertrophy of proximal astrocytes, which act as a protective layer by isolating areas of amyloid deposits via reactive gliosis. However, in the long term, gliosis restricts migration of endogenous and transplanted stem cells to the affected areas (158). IL-1 $\beta$, IL-6, TNF- $\alpha$ and TGF- $\beta$ secretion during the microglial immune response inhibit hippocampal neurogenesis and disrupt NSC proliferation (159). Despite the hostile niche of $\mathrm{AD}$, evidence shows that the cells can be prepared for this harsh cellular environment. In one investigation, hUC-MSCs were conditioned in AD patients' CSF before administration, and stem cells were observed to upregulate the transcription of transport and signal peptide genes. This finding suggests that pre-adaptation to the pathologic niche may enhance the therapeutic potential of stem cells in $\mathrm{AD}(160)$. Furthermore, the damage afflicted by $\mathrm{A} \beta$ and tau aggregate is not uniform across brain areas (156), and their patterns of distribution exhibit moderate overlap. A recent imaging study suggests that $A \beta$ patterns coincide with anterior and posterior areas of the default functional network, whereas tau accumulated over a wider range of networks (e.g., visual, somatosensory, language), and also solely disrupted white matter integrity (161). Moreover, the presence of the blood-brain barrier (BBB) significantly hinders intravascular delivery and supports direct implantation techniques, such as stereotactic surgery (162). This has been shown to be safe in the case of MSCs in a phase I trial (79). Despite the promising results in humans, cells still need to engraft in widespread areas, distal from the area of infusion, and overcome the hostile AD microenvironment. Murine and human NSCs and MSCs that were selected based on better migratory potential in vitro exhibited better homing and efficacy when stereotactically implanted in model mice (163). Cell lines could be screened beforehand for their motile capacity. As for protection from harsh niche conditions, biomimetic 3D scaffolds and neural tissue engineering have been proposed as possible interventions (164).

Another considerable obstacle arises from the fact that the $\mathrm{BBB}$ renders the brain an immune privileged organ, and cells may need to disrupt the barrier to access the brain parenchyma. This can trigger a potentially harmful local inflammatory response for the grafted cells (165). Concerns about generalized immune reactions such as encephalitis have also been voiced (166). Infiltration of leukocytes was observed towards xenogeneic (human), allogeneic, and syngeneic MSCs after intracerebral injection, especially in hMSCs, whose population was diminished after one week (167). Consequently, a less invasive transplantation technique focusing on the intravenous route has been developed, albeit with inconsistent results (162). Distribution of MSCs in the cerebral cortex of both wild-type and APP/PS1 mice after IV infusion was reported to be positively affected by the young age of the cells, older age of the mice, and positive mutation status (168). The intra-arterial route was only recently tested as a potential alternative, however engrafted cells were not detected in the brain parenchyma of mice post-infusion and were observed in brain vasculature only at the 5 -minute mark (169).

A major goal of regeneration research is to further understand the molecular mechanisms controlling 
regeneration and neuronal microenvironment.

\section{Conclusion and future perspectives}

$\mathrm{AD}$ is a progressive neurodegenerative disease, and since stem cells have the unique ability to regenerate, they may pose an effective treatment option. Despite advancements in stem cell technology, confirmed by encouraging preclinical utilization of stem cells in $\mathrm{AD}$ animal models, the number of clinical trials evaluating the efficacy of stem cell therapy is limited, with the results of many ongoing clinical trials on cell therapy for $\mathrm{AD}$ still pending. This is mainly due to limitations yet to be overcome, including technical considerations such as timing, dosing and an appropriate procedure for cell transplantation, none of which has been clearly determined. One of the disadvantages of stem cell therapy, like in any other organ transplant, is the need for immunosuppression; on the other hand, the use of progenitor cells may lead to tumor formation. Moreover, the anatomy and microenvironment of the brain exhibit significant differences among animal models and $\mathrm{AD}$ patients, and therefore precise characterization of the beneficial effects of stem cells in human $\mathrm{AD}$ has proven difficult. Human AD pathology mostly involves sporadic cases, while transgenic animal models have been developed for the familial type of AD. This limits the knowledge on how stem cell therapy would act in a patient-specific manner. Future work needs to address these questions. Future preclinical trials evaluating different sources, types, doses of stem cells, long-term safety, efficacy and precise mechanisms of action are required. In addition, iPSCbased therapy has made great progress in a short time. Footprint-free human iPSCs generation, genome editing, single cell and epigenome analysis technology are set to accelerate this process. However, iPSC-based therapy needs to overcome major limitations and prove to be safe before being utilized on patients. The use of genetically-modified stem cells using tissue engineering approaches may improve neurogenesis and synaptogenesis and therefore the underlying pathological hallmarks of $\mathrm{AD}$. Clinical trials so far have focused on the safety and efficacy of the engrafted cells, yet it is vital to shift emphasis towards uncovering the mode of action and the underlying therapeutic mechanisms of transplanted cells.

\section{Acknowledgments}

Funding: None.

\section{Footnote}

Conflicts of Interest: All authors have completed the ICMJE uniform disclosure form (available at https://sci.amegroups. com/article/view/10.21037/sci-2021-063/coif). The authors have no conflicts of interest to declare.

Etbical Statement: The authors are accountable for all aspects of the work in ensuring that questions related to the accuracy or integrity of any part of the work are appropriately investigated and resolved.

Open Access Statement: This is an Open Access article distributed in accordance with the Creative Commons Attribution-NonCommercial-NoDerivs 4.0 International License (CC BY-NC-ND 4.0), which permits the noncommercial replication and distribution of the article with the strict proviso that no changes or edits are made and the original work is properly cited (including links to both the formal publication through the relevant DOI and the license). See: https://creativecommons.org/licenses/by-nc-nd/4.0/.

\section{References}

1. Qiu C, Kivipelto M, von Strauss E. Epidemiology of Alzheimer's disease: occurrence, determinants, and strategies toward intervention. Dialogues Clin Neurosci 2009;11:111-28.

2. 2021 Alzheimer's disease facts and figures. Alzheimers Dement 2021;17:327-406.

3. GBD 2019 Collaborators. Global mortality from dementia: Application of a new method and results from the Global Burden of Disease Study 2019. Alzheimers Dement (N Y) 2021;7:e12200.

4. Maurer K, Maurer U. Alzheimer: The life of a physician and career of a disease. Columbia University Press, New York; 2003.

5. Fotuhi M, Hachinski V, Whitehouse PJ. Changing perspectives regarding late-life dementia. Nat Rev Neurol 2009;5:649-58.

6. Hardy J, Selkoe DJ. The amyloid hypothesis of Alzheimer's disease: progress and problems on the road to therapeutics. Science 2002;297:353-6.

7. Gandy S. The role of cerebral amyloid beta accumulation in common forms of Alzheimer disease. J Clin Invest 2005;115:1121-9.

8. Lambert MP, Barlow AK, Chromy BA, et al. Diffusible, nonfibrillar ligands derived from Abeta1-42 are potent 
central nervous system neurotoxins. Proc Natl Acad Sci U S A 1998;95:6448-53.

9. Ashe KH, Zahs KR. Probing the biology of Alzheimer's disease in mice. Neuron 2010;66:631-45.

10. Spires TL, Meyer-Luehmann M, Stern EA, et al. Dendritic spine abnormalities in amyloid precursor protein transgenic mice demonstrated by gene transfer and intravital multiphoton microscopy. J Neurosci 2005;25:7278-87.

11. William CM, Andermann ML, Goldey GJ, et al. Synaptic plasticity defect following visual deprivation in Alzheimer's disease model transgenic mice. J Neurosci 2012;32:8004-11.

12. Shankar GM, Bloodgood BL, Townsend M, et al. Natural oligomers of the Alzheimer amyloid-beta protein induce reversible synapse loss by modulating an NMDA-type glutamate receptor-dependent signaling pathway. J Neurosci 2007;27:2866-75.

13. Walsh DM, Klyubin I, Fadeeva JV, et al. Naturally secreted oligomers of amyloid beta protein potently inhibit hippocampal long-term potentiation in vivo. Nature 2002;416:535-9.

14. Chen QS, Wei WZ, Shimahara T, et al. Alzheimer amyloid beta-peptide inhibits the late phase of long-term potentiation through calcineurin-dependent mechanisms in the hippocampal dentate gyrus. Neurobiol Learn Mem 2002;77:354-71.

15. Shankar GM, Li S, Mehta TH, et al. Amyloid-beta protein dimers isolated directly from Alzheimer's brains impair synaptic plasticity and memory. Nat Med 2008;14:837-42.

16. Selkoe DJ. Alzheimer's disease is a synaptic failure. Science 2002;298:789-91.

17. Haass C, Selkoe DJ. Soluble protein oligomers in neurodegeneration: lessons from the Alzheimer's amyloid beta-peptide. Nat Rev Mol Cell Biol 2007;8:101-12.

18. Sheng M, Sabatini BL, Südhof TC. Synapses and Alzheimer's disease. Cold Spring Harb Perspect Biol 2012;4:a005777.

19. Um JW, Nygaard HB, Heiss JK, et al. Alzheimer amyloid- $\beta$ oligomer bound to postsynaptic prion protein activates Fyn to impair neurons. Nat Neurosci 2012;15:1227-35.

20. Laurén J, Gimbel DA, Nygaard HB, et al. Cellular prion protein mediates impairment of synaptic plasticity by amyloid-beta oligomers. Nature 2009;457:1128-32.

21. Cissé M, Halabisky B, Harris J, et al. Reversing EphB2 depletion rescues cognitive functions in Alzheimer model. Nature 2011;469:47-52.
22. Wang X, Takata T, Bai X, et al. Pyruvate prevents the inhibition of the long-term potentiation induced by amyloid- $\beta$ through protein phosphatase $2 \mathrm{~A}$ inactivation. J Alzheimers Dis 2012;30:665-73.

23. Taoufik E, Kouroupi G, Zygogianni O, et al. Synaptic dysfunction in neurodegenerative and neurodevelopmental diseases: an overview of induced pluripotent stem-cellbased disease models. Open Biol 2018;8:180138.

24. Riley J, Glass J, Feldman EL, et al. Intraspinal stem cell transplantation in amyotrophic lateral sclerosis: a phase I trial, cervical microinjection, and final surgical safety outcomes. Neurosurgery 2014;74:77-87.

25. Selden NR, Al-Uzri A, Huhn SL, et al. Central nervous system stem cell transplantation for children with neuronal ceroid lipofuscinosis. J Neurosurg Pediatr 2013;11:643-52.

26. Kumar V, Jahan S, Singh S, et al. Progress toward the development of in vitro model system for chemicalinduced developmental neurotoxicity: potential applicability of stem cells. Arch Toxicol 2015;89:265-7.

27. Monti M, Perotti C, Del Fante C, et al. Stem cells: sources and therapies. Biol Res 2012;45:207-14.

28. Condic ML. Totipotency: what it is and what it is not. Stem Cells Dev 2014;23:796-812.

29. Romito A, Cobellis G. Pluripotent Stem Cells: Current Understanding and Future Directions. Stem Cells Int 2016;2016:9451492.

30. Yamanaka S, Blau HM. Nuclear reprogramming to a pluripotent state by three approaches. Nature 2010;465:704-12.

31. Verfaillie CM. Adult stem cells: assessing the case for pluripotency. Trends Cell Biol 2002;12:502-8.

32. Sobhani A, Khanlarkhani N, Baazm M, et al. Multipotent Stem Cell and Current Application. Acta Med Iran 2017;55:6-23.

33. Pittenger MF, Mackay AM, Beck SC, et al. Multilineage potential of adult human mesenchymal stem cells. Science 1999;284:143-7.

34. Prockop DJ. Marrow stromal cells as stem cells for nonhematopoietic tissues. Science 1997;276:71-4.

35. Gronthos S, Simmons PJ. The biology and application of human bone marrow stromal cell precursors. J Hematother 1996;5:15-23.

36. Gage FH. Mammalian neural stem cells. Science 2000;287:1433-8.

37. Ishii T, Eto K. Fetal stem cell transplantation: Past, present, and future. World J Stem Cells 2014;6:404-20.

38. Martello G, Smith A. The nature of embryonic stem cells. Annu Rev Cell Dev Biol 2014;30:647-75. 
39. Damdimopoulou P, Rodin S, Stenfelt S, et al. Human embryonic stem cells. Best Pract Res Clin Obstet Gynaecol 2016;31:2-12.

40. Axell MZ, Zlateva S, Curtis M. A method for rapid derivation and propagation of neural progenitors from human embryonic stem cells. J Neurosci Methods 2009; 184:275-84.

41. Nistor G, Siegenthaler MM, Poirier SN, et al. Derivation of high purity neuronal progenitors from human embryonic stem cells. PLoS One 2011;6:e20692.

42. Noisa P, Raivio T, Cui W. Neural Progenitor Cells Derived from Human Embryonic Stem Cells as an Origin of Dopaminergic Neurons. Stem Cells Int 2015;2015:647437.

43. Hu Y, Qu ZY, Cao SY, et al. Directed differentiation of basal forebrain cholinergic neurons from human pluripotent stem cells. J Neurosci Methods 2016;266:42-9.

44. Bissonnette CJ, Lyass L, Bhattacharyya BJ, et al. The controlled generation of functional basal forebrain cholinergic neurons from human embryonic stem cells. Stem Cells 2011;29:802-11.

45. Schliebs R, Arendt T. The cholinergic system in aging and neuronal degeneration. Behav Brain Res 2011;221:555-63.

46. Arendt T, Bigl V, Arendt A, et al. Loss of neurons in the nucleus basalis of Meynert in Alzheimer's disease, paralysis agitans and Korsakoff's Disease. Acta Neuropathol 1983;61:101-8.

47. Yue W, Li Y, Zhang T, et al. ESC-Derived Basal Forebrain Cholinergic Neurons Ameliorate the Cognitive Symptoms Associated with Alzheimer's Disease in Mouse Models. Stem Cell Reports 2015;5:776-90.

48. Liu Y, Weick JP, Liu H, et al. Medial ganglionic eminencelike cells derived from human embryonic stem cells correct learning and memory deficits. Nat Biotechnol 2013;31:440-7.

49. Moghadam FH, Alaie H, Karbalaie K, et al.

Transplantation of primed or unprimed mouse embryonic stem cell-derived neural precursor cells improves cognitive function in Alzheimerian rats. Differentiation 2009;78:59-68.

50. Bao H, Song J. Treating Brain Disorders by Targeting Adult Neural Stem Cells. Trends Mol Med 2018;24:991-1006.

51. Boese AC, Hamblin MH, Lee JP. Neural stem cell therapy for neurovascular injury in Alzheimer's disease. Exp Neurol 2020;324:113112.

52. Su P, Zhang J, Zhao F, et al. The interaction between microglia and neural stem/precursor cells. Brain Res Bull 2014;109:32-8.
53. Marsh SE, Blurton-Jones M. Neural stem cell therapy for neurodegenerative disorders: The role of neurotrophic support. Neurochem Int 2017;106:94-100.

54. Homem CC, Repic M, Knoblich JA. Proliferation control in neural stem and progenitor cells. Nat Rev Neurosci 2015;16:647-59.

55. Zhu Q, Zhang N, Hu N, et al. Neural stem cell transplantation improves learning and memory by protecting cholinergic neurons and restoring synaptic impairment in an amyloid precursor protein/presenilin 1 transgenic mouse model of Alzheimer's disease. Mol Med Rep 2020;21:1172-80.

56. Zhang Q, Wu HH, Wang Y, et al. Neural stem cell transplantation decreases neuroinflammation in a transgenic mouse model of Alzheimer's disease. J Neurochem 2016;136:815-25.

57. Lee IS, Jung K, Kim IS, et al. Human neural stem cells alleviate Alzheimer-like pathology in a mouse model. Mol Neurodegener 2015;10:38.

58. Ager RR, Davis JL, Agazaryan A, et al. Human neural stem cells improve cognition and promote synaptic growth in two complementary transgenic models of Alzheimer's disease and neuronal loss. Hippocampus 2015;25:813-26.

59. McGinley LM, Kashlan ON, Bruno ES, et al. Human neural stem cell transplantation improves cognition in a murine model of Alzheimer's disease. Sci Rep 2018;8:14776.

60. Marsh SE, Yeung ST, Torres M, et al. HuCNS-SC Human NSCs Fail to Differentiate, Form Ectopic Clusters, and Provide No Cognitive Benefits in a Transgenic Model of Alzheimer's Disease. Stem Cell Reports 2017;8:235-48.

61. ChiCTR2000028744. A single center, randomized, double blind, placebo parallel controlled trial for human neural stem cells (ANGE S004) in the treatment of Alzheimer's disease. Chinese Clinical Trial Registry. Available online: https://www.chictr.org.cn/showprojen.aspx?proj=47760. Accessed 2 Jan 2020.

62. ChiCTR2000039011. Effect of human neural stem cells on patients with moderate to severe early-onset Alzheimer's disease clinical study on safety and effectiveness. Chinese Clinical Trial Registry. Available online: https://www. chictr.org.cn/showprojen.aspx?proj=61608. Accessed 13 Oct 2020.

63. ChiCTR-ONC-17014171. Clinical study of autologous neural stem cells to treat Alzheimer's disease. Chinese Clinical Trial Registry. Available online: https://www. chictr.org.cn/showprojen.aspx?proj=24246. Accessed 27 Dec 2017. 
64. Wei X, Yang X, Han ZP, et al. Mesenchymal stem cells: a new trend for cell therapy. Acta Pharmacol Sin 2013;34:747-54.

65. Joyce N, Annett G, Wirthlin L, et al. Mesenchymal stem cells for the treatment of neurodegenerative disease. Regen Med 2010;5:933-46.

66. Andrzejewska A, Lukomska B, Janowski M. Concise Review: Mesenchymal Stem Cells: From Roots to Boost. Stem Cells 2019;37:855-64.

67. Colpo GD, Ascoli BM, Wollenhaupt-Aguiar B, et al. Mesenchymal stem cells for the treatment of neurodegenerative and psychiatric disorders. An Acad Bras Cienc 2015;87:1435-49.

68. Garcia KO, Ornellas FL, Martin PK, et al. Therapeutic effects of the transplantation of VEGF overexpressing bone marrow mesenchymal stem cells in the hippocampus of murine model of Alzheimer's disease. Front Aging Neurosci 2014;6:30.

69. Kim DH, Lee D, Chang EH, et al. GDF-15 secreted from human umbilical cord blood mesenchymal stem cells delivered through the cerebrospinal fluid promotes hippocampal neurogenesis and synaptic activity in an Alzheimer's disease model. Stem Cells Dev 2015;24:2378-90.

70. Lee HJ, Lee JK, Lee H, et al. Human umbilical cord blood-derived mesenchymal stem cells improve neuropathology and cognitive impairment in an Alzheimer's disease mouse model through modulation of neuroinflammation. Neurobiol Aging 2012;33:588-602.

71. Lee JK, Jin HK, Endo S, et al. Intracerebral transplantation of bone marrow-derived mesenchymal stem cells reduces amyloid-beta deposition and rescues memory deficits in Alzheimer's disease mice by modulation of immune responses. Stem Cells 2010;28:329-43.

72. Naaldijk Y, Jäger C, Fabian C, et al. Effect of systemic transplantation of bone marrow-derived mesenchymal stem cells on neuropathology markers in APP/PS1 Alzheimer mice. Neuropathol Appl Neurobiol 2017;43:299-314.

73. Ding DC, Chang YH, Shyu WC, et al. Human umbilical cord mesenchymal stem cells: a new era for stem cell therapy. Cell Transplant 2015;24:339-47.

74. Boutajangout A, Noorwali A, Atta H, et al. Human Umbilical Cord Stem Cell Xenografts Improve Cognitive Decline and Reduce the Amyloid Burden in a Mouse Model of Alzheimer's Disease. Curr Alzheimer Res 2017;14:104-11.

75. Xie ZH, Liu Z, Zhang XR, et al. Wharton's Jelly-derived mesenchymal stem cells alleviate memory deficits and reduce amyloid- $\beta$ deposition in an APP/PS1 transgenic mouse model. Clin Exp Med 2016;16:89-98.

76. Cui Y, Ma S, Zhang C, et al. Human umbilical cord mesenchymal stem cells transplantation improves cognitive function in Alzheimer's disease mice by decreasing oxidative stress and promoting hippocampal neurogenesis. Behav Brain Res 2017;320:291-301.

77. Lykhmus O, Voytenko L, Koval L, et al. $\alpha 7$ Nicotinic acetylcholine receptor-specific antibody induces inflammation and amyloid $\beta 42$ accumulation in the mouse brain to impair memory. PLoS One 2015;10:e0122706.

78. Lykhmus O, Koval L, Voytenko L, et al. Intravenously Injected Mesenchymal Stem Cells Penetrate the Brain and Treat Inflammation-Induced Brain Damage and Memory Impairment in Mice. Front Pharmacol 2019;10:355.

79. Kim HJ, Seo SW, Chang JW, et al. Stereotactic brain injection of human umbilical cord blood mesenchymal stem cells in patients with Alzheimer's disease dementia: A phase 1 clinical trial. Alzheimers Dement (N Y) 2015;1:95-102.

80. Ltd. MC. The Safety and The Efficacy Evaluation of NEUROSTEM®-AD in Patients With Alzheimer's Disease. 2011. Available online: https://clinicaltrials.gov/ ct2/show/NCT01297218. Accessed April 23, 2012.

81. Na DL, Ltd. MC, Center SM. The Long-Term Safety and Efficacy Follow-Up Study of Subjects Who Completed the Phase I Clinical Trial of Neurostem ${ }_{-A D}$-AD 2012. Available online: https://clinicaltrials.gov/show/NCT01696591. Accessed October 1, 2012.

82. Ltd. MC. Safety and Exploratory Efficacy Study of NEUROSTEM@ Versus Placebo in Patients With Alzheimer's Disease. 2014. Available online: https:// clinicaltrials.gov/show/NCT02054208. Accessed August 28, 2020.

83. Kim HJ, Cho KR, Jang H, et al. Intracerebroventricular injection of human umbilical cord blood mesenchymal stem cells in patients with Alzheimer's disease dementia: a phase I clinical trial. Alzheimers Res Ther 2021;13:154.

84. Ltd. MC. Follow-up Study of Safety and Efficacy in Subjects Who Completed NEUROSTEM® Phase-I/IIa Clinical Trial. 2017. Available online: https://clinicaltrials. gov/show/NCT03172117. Accessed August 28, 2020.

85. Center SM, Ltd. MC. Exploratory Efficacy Study of NEUROSTEM® in Subjects Who Control Group of NEUROSTEM®. 2021. Available online: https:// clinicaltrials.gov/ct2/show/NCT04954534. Accessed July 14, 2021.

86. Sciences AHtAoMM, Hospital PUT. Safety and 
Efficiency of Umbilical Cord-derived Mesenchymal Stem Cells(UC-MSC) in Patients With Alzheimer's Disease. 2012. Available online: https://clinicaltrials.gov/show/ NCT01547689. Accessed February 22, 2016.

87. Cell SCRCfS, Medicine R, PLA GGHoGMCo, et al. Safety and Exploratory Efficacy Study of UCMSCs in Patients With Alzheimer's Disease. 2017. Available online: https://clinicaltrials.gov/show/NCT02672306. Accessed April 26, 2018.

88. Baumel B, Miami Uo. Alzheimer's Disease Stem Cells Multiple Infusions. 2019. Available online: https:// clinicaltrials.gov/show/NCT04040348. Accessed December 14, 2021.

89. Cell RS. Safety and Clinical Outcomes With Amniotic and Umbilical Cord Tissue Therapy for Numerous Medical Conditions. 2019. Available online: https://clinicaltrials. gov/show/NCT03899298. Accessed August 22, 2019.

90. LLC TAM, Institute H, NuStem. Mesenchymal Stem Cells for the Treatment of Various Chronic and Acute Conditions. Available online: https://clinicaltrials.gov/ct2/ show/NCT04684602. Accessed December 24, 2020.

91. CHABiotech CO. L. Evaluation of the Safety and Potential Therapeutic Effects After Intravenous Transplantation of CB-AC-02 in Patients With Alzheimer's Disease. 2016. Available online: https://clinicaltrials.gov/show/ NCT02899091. Accessed September 6, 2019.

92. Yeh DC, Chan TM, Harn HJ, et al. Adipose tissue-derived stem cells in neural regenerative medicine. Cell Transplant 2015;24:487-92.

93. Ma T, Gong K, Ao Q, et al. Intracerebral transplantation of adipose-derived mesenchymal stem cells alternatively activates microglia and ameliorates neuropathological deficits in Alzheimer's disease mice. Cell Transplant 2013;22 Suppl 1:S113-26.

94. Kim S, Chang KA, Kim Ja, et al. The preventive and therapeutic effects of intravenous human adiposederived stem cells in Alzheimer's disease mice. PLoS One 2012;7:e45757.

95. Nasiri E, Alizadeh A, Roushandeh AM, et al. Melatoninpretreated adipose-derived mesenchymal stem cells efficeintly improved learning, memory, and cognition in an animal model of Alzheimer's disease. Metab Brain Dis 2019;34:1131-43.

96. Duma C, Kopyov O, Kopyov A, et al. Human intracerebroventricular (ICV) injection of autologous, non-engineered, adipose-derived stromal vascular fraction (ADSVF) for neurodegenerative disorders: results of a 3 -year phase 1 study of 113 injections in 31 patients. Mol
Biol Rep 2019;46:5257-72.

97. Lander E, Inc. CSN. Safety and Clinical Outcomes Study: SVF Deployment for Orthopedic, Neurologic, Urologic, and Cardio-pulmonary Conditions. 2013. Available online: https://clinicaltrials.gov/ct2/show/NCT01953523. Accessed September 25, 2018

98. Ltd. NCC. A Study to Evaluate the Safety and Efficacy of AstroStem in Treatment of Alzheimer's Disease. 2017. Available online: https://clinicaltrials.gov/show/ NCT03117738. Accessed August 10, 2021.

99. Ltd. NCC. Study to Evaluate the Safety and Efficacy of AstroStem in Treatment of Alzheimer's Disease. 2021. Available online: https://clinicaltrials.gov/show/ NCT04482413. Accessed March 26, 2021.

100. Foundation HBSCR, Biosciences H. A Clinical Trial to Determine the Safety and Efficacy of Hope Biosciences Autologous Mesenchymal Stem Cell Therapy (HBadMSCs) for the Treatment of Alzheimer's Disease. 2020. Available online: https://clinicaltrials.gov/show/ NCT04228666. Accessed July 7, 2021.

101. Medical R, Medicine GAfR, Robert W. Alexander M, FICS, et al. Autologous Stem/Stromal Cells in Neurological Disorders and Disease. 2020. Available online: https://clinicaltrials.gov/show/NCT03297177. Accessed October 18, 2018.

102.JPRN-jRCTb030190214. Exploratory clinical study of Alzheimer's disease by using Autologous adipose-derived mesenchymal stem cell. Registered date: 07/02/2020.

103. Corporation CT. Autologous Human Adipose-Derived Mesenchymal Stem Cells in Alzheimer's Disease. Available online: https://clinicaltrials.gov/ct2/show/study/ NCT04855955. Accessed April 22, 2021.

104. Hospital R, Ltd. CBG. the Safety and the Efficacy Evaluation of Allogenic Adipose MSC-Exos in Patients With Alzheimer's Disease. 2020. Available online: https:// www.clinicaltrials.gov/ct2/show/NCT04388982. Accessed June 25, 2021.

105.ChiCTR2000032579. To evaluate the safety and effectiveness of allogeneic human adipose-derived mesenchymal stem cell exosomes (ahaMSCs-Exo.) in the treatment of Alzheimer's disease (AD). Chinese Clinical Trial Registry. Available online: https://www.chictr.org.cn/ showproj.aspx? proj=51939. Accessed 3 May 2020.

106.Ma X, Huang M, Zheng M, et al. ADSCs-derived extracellular vesicles alleviate neuronal damage, promote neurogenesis and rescue memory loss in mice with Alzheimer's disease. J Control Release 2020;327:688-702. 107. Butreddy A, Kommineni N, Dudhipala N. Exosomes 
as Naturally Occurring Vehicles for Delivery of Biopharmaceuticals: Insights from Drug Delivery to Clinical Perspectives. Nanomaterials (Basel) 2021;11:1481.

108. Charbord P. Bone marrow mesenchymal stem cells: historical overview and concepts. Hum Gene Ther 2010;21:1045-56.

109. Ruzicka J, Kulijewicz-Nawrot M, Rodrigez-Arellano JJ, et al. Mesenchymal Stem Cells Preserve Working Memory in the 3xTg-AD Mouse Model of Alzheimer's Disease. Int J Mol Sci 2016;17:152.

110. Harach T, Jammes F, Muller C, et al. Administrations of human adult ischemia-tolerant mesenchymal stem cells and factors reduce amyloid beta pathology in a mouse model of Alzheimer's disease. Neurobiol Aging 2017;51:83-96.

111. Yokokawa K, Iwahara N, Hisahara S, et al. Transplantation of Mesenchymal Stem Cells Improves Amyloid- $\beta$ Pathology by Modifying Microglial Function and Suppressing Oxidative Stress. J Alzheimers Dis 2019;72:867-84.

112. Neves AF, Camargo C, Premer C, et al. Intravenous administration of mesenchymal stem cells reduces Tau phosphorylation and inflammation in the 3xTgAD mouse model of Alzheimer's disease. Exp Neurol 2021;341:113706.

113. Matchynski-Franks JJ, Pappas C, Rossignol J, et al. Mesenchymal Stem Cells as Treatment for Behavioral Deficits and Neuropathology in the 5xFAD Mouse Model of Alzheimer's Disease. Cell Transplant 2016;25:687-703.

114. Wei Y, Xie Z, Bi J, et al. Anti-inflammatory effects of bone marrow mesenchymal stem cells on mice with Alzheimer's disease. Exp Ther Med 2018;16:5015-20.

115. Qin C, Lu Y, Wang K, et al. Transplantation of bone marrow mesenchymal stem cells improves cognitive deficits and alleviates neuropathology in animal models of Alzheimer's disease: a meta-analytic review on potential mechanisms. Transl Neurodegener 2020;9:20.

116.Zhao Y, Chen X, Wu Y, et al. Transplantation of Human Menstrual Blood-Derived Mesenchymal Stem Cells Alleviates Alzheimer's Disease-Like Pathology in APP/ PS1 Transgenic Mice. Front Mol Neurosci 2018;11:140.

117.Inc. L. Allogeneic Human Mesenchymal Stem Cell Infusion Versus Placebo in Patients With Alzheimer's Disease. 2016. Available online: https://clinicaltrials.gov/ show/NCT02600130. Accessed December 14, 2021.

118. Stemedica Cell Technologies I, SA SI. Allogeneic Human Mesenchymal Stem Cells for Alzheimer's Disease. 2016. Available online: https://clinicaltrials.gov/show/ NCT02833792. Accessed October 29, 2020.

119. Cells MS. Alzheimer's Autism and Cognitive Impairment
Stem Cell Treatment Study. 2018. Available online: https://clinicaltrials.gov/show/NCT03724136. Accessed September 10, 2021.

120.EUCTR2020-002872-11-NL. An open-label study to assess safety and tolerability of NurOwn® in participants with early stage of Alzheimer's Disease. 2020.

121. Florida UoS. Efficacy and Safety of Filgrastim in Alzheimer's Disease. 2009. Available online: https:// clinicaltrials.gov/show/NCT01617577. Accessed December 27, 2012.

122. Hospital CGM. To Evaluate the Efficacy and Safety/ Tolerability Profiles of G-CSF in Subjects With Mild to Moderate Alzheimer's Disease. 2009. Available online: https://clinicaltrials.gov/ct2/show/NCT03656042. Accessed September 4, 2018.

123. Mehta HM, Malandra M, Corey SJ. G-CSF and GM-CSF in Neutropenia. J Immunol 2015;195:1341-9.

124. Bendall LJ, Bradstock KF. G-CSF: From granulopoietic stimulant to bone marrow stem cell mobilizing agent. Cytokine Growth Factor Rev 2014;25:355-67.

125.Hopman RK, DiPersio JF. Advances in stem cell mobilization. Blood Rev 2014;28:31-40.

126. Sanchez-Ramos J, Song S, Sava V, et al. Granulocyte colony stimulating factor decreases brain amyloid burden and reverses cognitive impairment in Alzheimer's mice. Neuroscience 2009; 163:55-72.

127.Wu CC, Wang IF, Chiang PM, et al. G-CSF-mobilized Bone Marrow Mesenchymal Stem Cells Replenish Neural Lineages in Alzheimer's Disease Mice via CXCR4/SDF-1 Chemotaxis. Mol Neurobiol 2017;54:6198-212.

128. Robinton DA, Daley GQ. The promise of induced pluripotent stem cells in research and therapy. Nature 2012;481:295-305.

129. Takahashi K, Yamanaka S. Induction of pluripotent stem cells from mouse embryonic and adult fibroblast cultures by defined factors. Cell 2006;126:663-76.

130. Takahashi K, Tanabe K, Ohnuki M, et al. Induction of pluripotent stem cells from adult human fibroblasts by defined factors. Cell 2007;131:861-72.

131. D'Aiuto L, Zhi Y, Kumar Das D, et al. Large-scale generation of human iPSC-derived neural stem cells/early neural progenitor cells and their neuronal differentiation. Organogenesis 2014;10:365-77.

132. Lam M, Sanosaka T, Lundin A, et al. Single-cell study of neural stem cells derived from human iPSCs reveals distinct progenitor populations with neurogenic and gliogenic potential. Genes Cells 2019;24:836-47.

133. Ford E, Pearlman J, Ruan T, et al. Human Pluripotent 
Stem Cells-Based Therapies for Neurodegenerative Diseases: Current Status and Challenges. Cells 2020;9:2517.

134. Fujiwara N, Shimizu J, Takai K, et al. Restoration of spatial memory dysfunction of human APP transgenic mice by transplantation of neuronal precursors derived from human iPS cells. Neurosci Lett 2013;557 Pt B:129-34.

135. Fujiwara N, Shimizu J, Takai K, et al. Cellular and molecular mechanisms of the restoration of human APP transgenic mouse cognitive dysfunction after transplant of human iPS cell-derived neural cells. Exp Neurol 2015;271:423-31.

136. Armijo E, Edwards G, Flores A, et al. Induced Pluripotent Stem Cell-Derived Neural Precursors Improve Memory, Synaptic and Pathological Abnormalities in a Mouse Model of Alzheimer's Disease. Cells 2021;10:1802.

137. Cha MY, Kwon YW, Ahn HS, et al. Protein-Induced Pluripotent Stem Cells Ameliorate Cognitive Dysfunction and Reduce A $\beta$ Deposition in a Mouse Model of Alzheimer's Disease. Stem Cells Transl Med 2017;6:293-305.

138. Takamatsu K, Ikeda T, Haruta M, et al. Degradation of amyloid beta by human induced pluripotent stem cellderived macrophages expressing Neprilysin-2. Stem Cell Res 2014;13:442-53.

139. Rosati J, Ferrari D, Altieri F, et al. Establishment of stable iPS-derived human neural stem cell lines suitable for cell therapies. Cell Death Dis 2018;9:937.

140.Saunders A, Macosko EZ, Wysoker A, et al. Molecular Diversity and Specializations among the Cells of the Adult Mouse Brain. Cell 2018;174:1015-1030.e16.

141.Morgan SE, White SR, Bullmore ET, et al. A Network Neuroscience Approach to Typical and Atypical Brain Development. Biol Psychiatry Cogn Neurosci Neuroimaging 2018;3:754-66.

142.Lugert S, Basak O, Knuckles P, et al. Quiescent and active hippocampal neural stem cells with distinct morphologies respond selectively to physiological and pathological stimuli and aging. Cell Stem Cell 2010;6:445-56.

143. Andreotti JP, Silva WN, Costa AC, et al. Neural stem cell niche heterogeneity. Semin Cell Dev Biol 2019;95:42-53.

144. Ma DK, Bonaguidi MA, Ming GL, et al. Adult neural stem cells in the mammalian central nervous system. Cell Res 2009;19:672-82.

145. Christian KM, Song H, Ming GL. Functions and dysfunctions of adult hippocampal neurogenesis. Annu Rev Neurosci 2014;37:243-62.

146.Zhang GL, Zhu ZH, Wang YZ. Neural stem cell transplantation therapy for brain ischemic stroke: Review and perspectives. World J Stem Cells 2019;11:817-30.

147.Li L, Clevers H. Coexistence of quiescent and active adult stem cells in mammals. Science 2010;327:542-5.

148.Lilja AM, Malmsten L, Röjdner J, et al. Neural Stem Cell Transplant-Induced Effect on Neurogenesis and Cognition in Alzheimer Tg2576 Mice Is Inhibited by Concomitant Treatment with Amyloid-Lowering or Cholinergic $\alpha 7$ Nicotinic Receptor Drugs. Neural Plast 2015;2015:370432.

149. Rockenstein E, Desplats P, Ubhi K, et al. Neuro-peptide treatment with Cerebrolysin improves the survival of neural stem cell grafts in an APP transgenic model of Alzheimer disease. Stem Cell Res 2015;15:54-67.

150.Fricker RA, Carpenter MK, Winkler C, et al. Site-specific migration and neuronal differentiation of human neural progenitor cells after transplantation in the adult rat brain. J Neurosci 1999;19:5990-6005.

151.Ladewig J, Koch P, Brüstle O. Auto-attraction of neural precursors and their neuronal progeny impairs neuronal migration. Nat Neurosci 2014;17:24-6.

152. Rakic P. Elusive radial glial cells: historical and evolutionary perspective. Glia 2003;43:19-32.

153. Gebara E, Bonaguidi MA, Beckervordersandforth R, et al. Heterogeneity of Radial Glia-Like Cells in the Adult Hippocampus. Stem Cells 2016;34:997-1010.

154. Gonzalez R, Hamblin MH, Lee JP. Neural Stem Cell Transplantation and CNS Diseases. CNS Neurol Disord Drug Targets 2016;15:881-6.

155. Boche D, Nicoll JAR. Invited Review - Understanding cause and effect in Alzheimer's pathophysiology: Implications for clinical trials. Neuropathol Appl Neurobiol 2020;46:623-40.

156.Li XY, Bao XJ, Wang RZ. Potential of neural stem cellbased therapies for Alzheimer's disease. J Neurosci Res 2015;93:1313-24.

157.Lee IS, Jung K, Kim IS, et al. Amyloid- $\beta$ oligomers regulate the properties of human neural stem cells through GSK-3 $\beta$ signaling. Exp Mol Med 2013;45:e60.

158. Robel S, Berninger B, Götz M. The stem cell potential of glia: lessons from reactive gliosis. Nat Rev Neurosci 2011;12:88-104.

159.Horgusluoglu E, Nudelman K, Nho K, et al. Adult neurogenesis and neurodegenerative diseases: A systems biology perspective. Am J Med Genet B Neuropsychiatr Genet 2017;174:93-112.

160.Lee J, Kwon SJ, Kim JH, et al. Cerebrospinal fluid from Alzheimer's disease patients as an optimal formulation 
for therapeutic application of mesenchymal stem cells in Alzheimer's disease. Sci Rep 2019;9:564.

161.Pereira JB, Ossenkoppele R, Palmqvist S, et al. Amyloid and tau accumulate across distinct spatial networks and are differentially associated with brain connectivity. Elife 2019;8:50830.

162. Salem H, Rocha NP, Colpo GD, et al. Moving from the Dish to the Clinical Practice: A Decade of Lessons and Perspectives from the Pre-Clinical and Clinical Stem Cell Studies for Alzheimer's Disease. J Alzheimers Dis 2016;53:1209-30.

163. Danielyan L, Schwab M, Siegel G, et al. Cell motility and migration as determinants of stem cell efficacy. EBioMedicine 2020;60:102989.

164. Alipour M, Nabavi SM, Arab L, et al. Stem cell therapy in Alzheimer's disease: possible benefits and limiting drawbacks. Mol Biol Rep 2019;46:1425-46.

165. Chiu AY, Rao MS. Cell-based therapy for neural disorders- -anticipating challenges. Neurotherapeutics 2011;8:74452.

166. Hunsberger JG, Rao M, Kurtzberg J, et al. Accelerating stem cell trials for Alzheimer's disease. Lancet Neurol 2016;15:219-30.

167. Hwang JW, Lee NK, Yang JH, et al. A Comparison of Immune Responses Exerted Following Syngeneic, Allogeneic, and Xenogeneic Transplantation of Mesenchymal Stem Cells into the Mouse Brain. Int J Mol Sci 2020;21:3052.

168. Fabian C, Naaldijk Y, Leovsky C, et al. Distribution pattern following systemic mesenchymal stem cell injection depends on the age of the recipient and neuronal health. Stem Cell Res Ther 2017;8:85.

169. Lee NK, Yang J, Chang EH, et al. Intra-Arterially Delivered Mesenchymal Stem Cells Are Not Detected in the Brain Parenchyma in an Alzheimer's Disease Mouse Model. PLoS One 2016;11:e0155912. doi: $10.21037 /$ sci-2021-063

Cite this article as: Karvelas N, Bennett S, Politis G, Kouris NI, Kole C. Advances in stem cell therapy in Alzheimer's disease: a comprehensive clinical trial review. Stem Cell Investig 2022;9:2. 